\title{
LHomme
}

L'HOMME Revue française d'anthropologie

$190 \mid 2009$

Varia

\section{Jérôme Garcin, ed., Nouvelles Mythologies}

\section{Yves Laberge}

\section{(2) OpenEdition}

Journals

Édition électronique

URL : http://journals.openedition.org/lhomme/28752

DOl : 10.4000//homme.28752

ISSN : 1953-8103

\section{Éditeur}

Éditions de l'EHESS

\section{Édition imprimée}

Date de publication : 1 janvier 2009

Pagination : 249-250

ISSN : 0439-4216

\section{Référence électronique}

Yves Laberge, « Jérôme Garcin, ed., Nouvelles Mythologies », L'Homme [En ligne], 190 | 2009, mis en ligne le 03 janvier 2017, consulté le 21 décembre 2020. URL : http://journals.openedition.org/lhomme/ 28752 ; DOI : https://doi.org/10.4000//homme.28752

Ce document a été généré automatiquement le 21 décembre 2020.

(c) École des hautes études en sciences sociales 


\title{
Jérôme Garcin, ed., Nouvelles Mythologies
}

\author{
Yves Laberge
}

\section{RÉFÉRENCE}

Jérôme GARCIN, ed., Nouvelles Mythologies, Paris, Le Seuil, 2007, 186 p., notes bibliogr., ill.

1 L'IDÉE est excellente et il fallait y penser : les Mythologies ${ }^{1}$ de Roland Barthes avaient marqué l'univers de l'essai en France et demeurent une référence unique pour mieux saisir certains traits spécifiques de la pensée française du milieu du $x^{e}$ siècle. Sur un tout autre mode, Gustave Flaubert avait bien rédigé son Dictionnaire des idées reçues. Seul le temps pouvait peut-être affaiblir les Mythologies de Barthes ; en relisant ce livre après plus de cinquante années, on constate que l'appareil critique demeure intact, mais les référents culturels risquent parfois de perdre leurs significations et leur valeur symbolique auprès des nouvelles générations de lecteurs. Pourtant, Barthes innovait doublement : d'abord, il s'intéressait à des objets du quotidien, dont on ne remarquait pas la valeur symbolique, emblématique, voire iconique; et par ailleurs, il les analysait scientifiquement selon une perspective alors méconnue en France, non pas d'après l'anthropologie ou la sociologie, mais bien selon une méthode dérivée de la sémiologie. Dans ces sublimes Mythologies de Barthes, c'était toute la France d'après-guerre qui était décortiquée à partir de certains produits typiques, de la publicité, de l'air du temps : la DS de Citroën, la frange des acteurs du grand écran voulant jouer les personnages de la Rome antique, les photographies toutes similaires provenant du studio Harcourt, et plusieurs autres.

2 Les Nouvelles Mythologies de Jérôme Garcin reprennent la méthode initiale de Barthes pour l'appliquer à d'autres objets : des faits de société propres à 2007. Une soixantaine d'auteurs et essayistes français ont été convoqués pour aborder brièvement un phénomène de société : le Speed-dating d'après Nelly Arcand, les journaux gratuits selon Patrick Besson, le téléphone portable vu par Philippe Delerm, la «Star Academy » selon 
Benoît Duteurtre. Parmi les textes les plus inspirés, on retiendra "La nouvelle Ève », où Pascal Bruckner constate à quel point beaucoup de femmes bourgeoises d'aujourd'hui s'exposent audacieusement (décolletés, nombril) tout en conservant des valeurs morales de leur rang: «Il est paradoxal que les femmes, ayant conquis leur indépendance, se constituent ainsi en objets érotiques » (p. 40).

3 Ailleurs, Patrick Mauriès décrit les célébrités de l'heure, «Les people », comme un petit univers à part, mais apparemment organisé et régi par des règles tacites : «Restreint, ce petit monde ne se livre qu'à des activités elles-mêmes comptées, guère plus de trois en apparence, dont la succession structure les magazines » (p. 113). Plus loin, Patrick Rambaud démontre comment le «blog " personnel sur internet pourrait désormais remplacer l'interminable récit de vacances en diapositives des générations précédentes (p.150). Dans un excellent passage, Daniel Sibony définit le mythe comme un «fantasme qui s'incarne pour un groupe, se fixe dans un récit, devient même un lieu commun qu'un public aime fréquenter » (p. 160).

4 Certains textes abordent un sujet tout à fait pertinent, symptomatique, mais dont l'exposé nous laisse parfois sur notre faim. Ainsi, Pierre Assouline ne parvient pas à cerner les conséquences de la réputation surfaite de l'écrivain Michel Houellebecq; Serge Raffy n'apporte aucune révélation à propos des «bobos »; Jacques-Alain Miller ne réussit pas à extraire du phénomène «Google» toute sa richesse symbolique ; Philippe Sollers n'épuise pas un sujet en or (!) comme l'euro. En dépit de ses faiblesses, ces Nouvelles Mythologies commandées par Jérôme Garcin me semblent dignes d'être lues, non seulement par les publicistes, mais par tout chercheur en sciences de l'homme.

\section{NOTES}

1. Paris, Le Seuil, 1970.

\section{AUTEURS}

\section{YVES LABERGE}

Association canadienne des études culturelles, Montréal (Canada).

Yves.Laberge@fp.ulaval.ca 